\title{
Mechanical Modeling of Porous Oxide Fuel Pellet - A Test Problem
}

Date: $14^{\text {th }}$ October 2009

\author{
Prepared by \\ Phani K. V. V. Nukala \\ Senior Scientist, ORNL, Oak Ridge, TN \\ Pallab Barai \\ PostMaster Research Associate, ORAU, Oak Ridge, TN \\ Srdjan Simunovic \\ Senior Scientist, ORNL, Oak Ridge, TN \\ Larry J. Ott \\ Senior Scientist, ORNL, Oak Ridge, TN
}




\title{
DOCUMENT AVAILABILITY
}

Reports produced after January 1, 1996, are generally available free via the U.S. Department of Energy (DOE) Information Bridge.

Web site http://www.osti.gov/bridge

Reports produced before January 1, 1996, may be purchased by members of the public from the following source.

\author{
National Technical Information Service \\ 5285 Port Royal Road \\ Springfield, VA 22161 \\ Telephone 703-605-6000 (1-800-553-6847) \\ TDD 703-487-4639 \\ Fax 703-605-6900 \\ E-mail info@ntis.gov \\ Web site http://www.ntis.gov/support/ordernowabout.htm
}

Reports are available to DOE employees, DOE contractors, Energy Technology Data Exchange (ETDE) representatives, and International Nuclear Information System (INIS) representatives from the following source.

Office of Scientific and Technical Information

P.O. Box 62

Oak Ridge, TN 37831

Telephone 865-576-8401

Fax 865-576-5728

E-mail reports@osti.gov

Web site http://www.osti.gov/contact.html

This report was prepared as an account of work sponsored by an agency of the United States Government. Neither the United States Government nor any agency thereof, nor any of their employees, makes any warranty, express or implied, or assumes any legal liability or responsibility for the accuracy, completeness, or usefulness of any information, apparatus, product, or process disclosed, or represents that its use would not infringe privately owned rights. Reference herein to any specific commercial product, process, or service by trade name, trademark, manufacturer, or otherwise, does not necessarily constitute or imply its endorsement, recommendation, or favoring by the United States Government or any agency thereof. The views and opinions of authors expressed herein do not necessarily state or reflect those of the United States Government or any agency thereof. 


\title{
MECHANICAL MODELING OF POROUS OXIDE FUEL PELLET - A TEST PROBLEM
}

\author{
Phani K. V. V. Nukala \\ Pallab Barai \\ Srdjan Simunovic \\ Larry J. Ott
}

Date Published: $14^{\text {th }}$ October 2009

Prepared by

OAK RIDGE NATIONAL LABORATORY

Oak Ridge, Tennessee 37831-6283

managed by

UT-BATTELLE, LLC

for the

U.S. DEPARTMENT OF ENERGY

under contract DE-AC05-00OR22725 



\section{CONTENTS}

\section{Page}

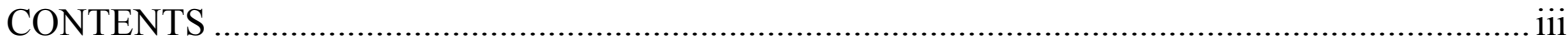

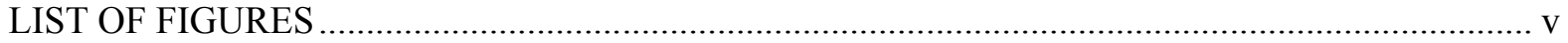

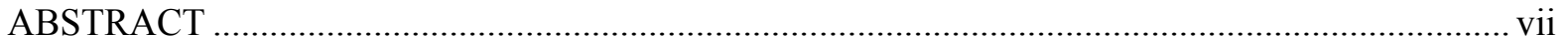

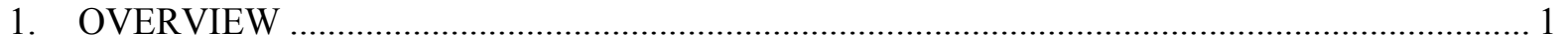

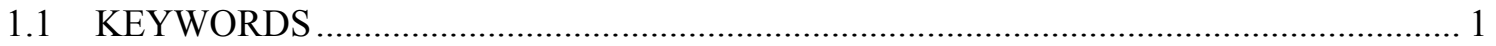

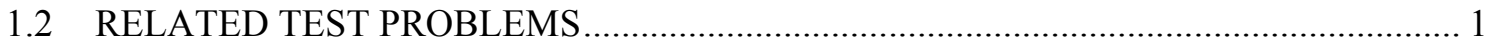

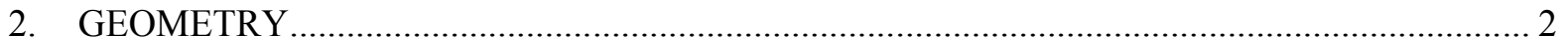

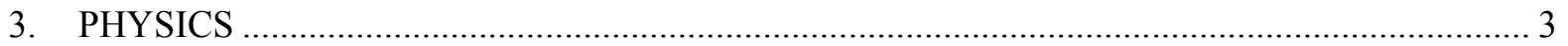

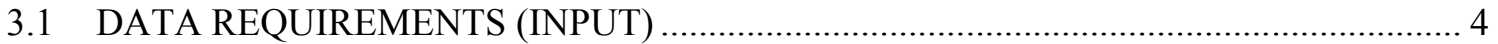

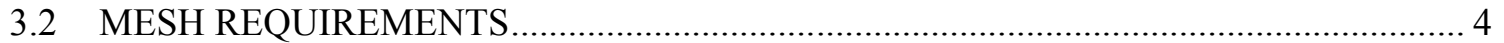

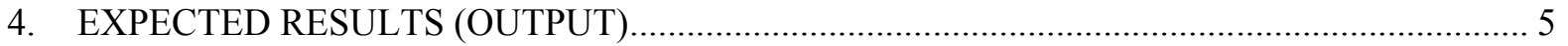

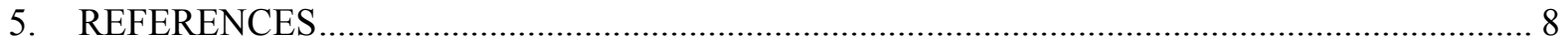

APPENDIX A. LIST OF MATERIAL PROPERTIES …........................................................... A - 3 



\section{LIST OF FIGURES}

Figure

Page

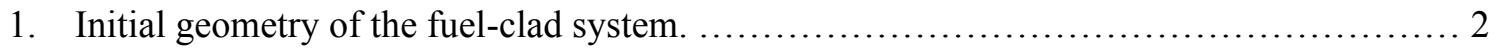

2. Evolution of the void fraction within the fuel pellet with initial void fraction $f=0.3 \ldots \ldots \ldots 3$

3. Evolution of the void fraction within the fuel pellet with random initial void fraction. ......4

4. Evolution of equivalent stress inside fuel-clad system with initial void fraction $0.3 . \ldots . . .5$

5. A comparative study for the evolution of volume fraction within the fuel pellets under constrained and free radial expansion of the clad outer surface. ......................... 6

6. Variation in the void volume fraction along any diameter (normalized between -0.5 to +0.5 ) inside the fuel-clad system. ....................................................... 6

7. A comparative study for the evolution of stress within the fuel-clad assembly with and without voids inside the fuel. 



\begin{abstract}
A poro-elasto-plastic material model has been developed to capture the response of oxide fuels inside the nuclear reactors under operating conditions. Behavior of the oxide fuel and variation in void volume fraction under mechanical loading as predicted by the developed model has been reported in this article. The significant effect of void volume fraction on the overall stress distribution of the fuel pellet has also been described.
\end{abstract}





\section{OVERVIEW}

An important oxide fuel issue that can have significant impact on the fuel performance is the mechanical response of oxide fuel pellet and clad system. Specifically, modeling the thermo-mechanical response of the fuel pellet in terms of its thermal expansion, mechanical deformation, swelling due to void formation and evolution, and the eventual contact of the fuel with the clad is of significant interest in understanding the fuel-clad mechanical interaction (FCMI). These phenomena are nonlinear and coupled since reduction in the fuel-clad gap affects thermal conductivity of the gap, which in turn affects temperature distribution within the fuel and the material properties of the fuel. Consequently, in order to accurately capture fuel-clad gap closure, we need to account for fuel swelling due to generation, retention, and evolution of fission gas in addition to the usual thermal expansion and mechanical deformation. Both fuel chemistry and microstructure also have a significant effect on the nucleation and growth of fission gas bubbles. Fuel-clad gap closure leading to eventual contact of the fuel with the clad introduces significant stresses in the clad, which makes thermo-mechanical response of the clad even more relevant.

The overall aim of this test problem is to incorporate the above features in order to accurately capture fuel-clad mechanical interaction. Because of the complex nature of the problem, a series of test problems with increasing multi-physics coupling features, modeling accuracy, and complexity are defined with the objective of accurate simulation of fuel-clad mechanical interaction subjected to a wide-range of thermomechanical stimuli.

\subsection{KEYWORDS}

Void volume fraction, elasticity, plasticity, nonlinear mechanics, and finite element method.

\subsection{RELATED TEST PROBLEMS}

None. 


\section{GEOMETRY}

Initially, before the reaction starts within the reactor, the oxide fuel is in the form of cylindrical pellets, 0.3225 inches in diameter and 0.387 inches long that are stacked vertically. The inner and outer diameters of the clad are 0.3290 and 0.3930 inches respectively. This implies a clad thickness of 0.032 inches. But in this test problem we concentrate on the particular case when due to burnup the fuel have expanded and touched the clad. The clad is $\mathrm{Zr}$ alloy and no gap is considered between fuel and the clad (Fig: 1). The combination of pellet and clad is free to expand in the radial directions under the axial compressive loading (usually in the nuclear reactor, the cladding is restrained from free expansion in the radial direction $[1,9])$. Since in this problem, the fuel has already gone through some burnup resulting in release of fission gas and expansion of the fuel pellet to touch the clad, an arbitrary distribution of voids within the pellet is assumed to initialize the simulations.

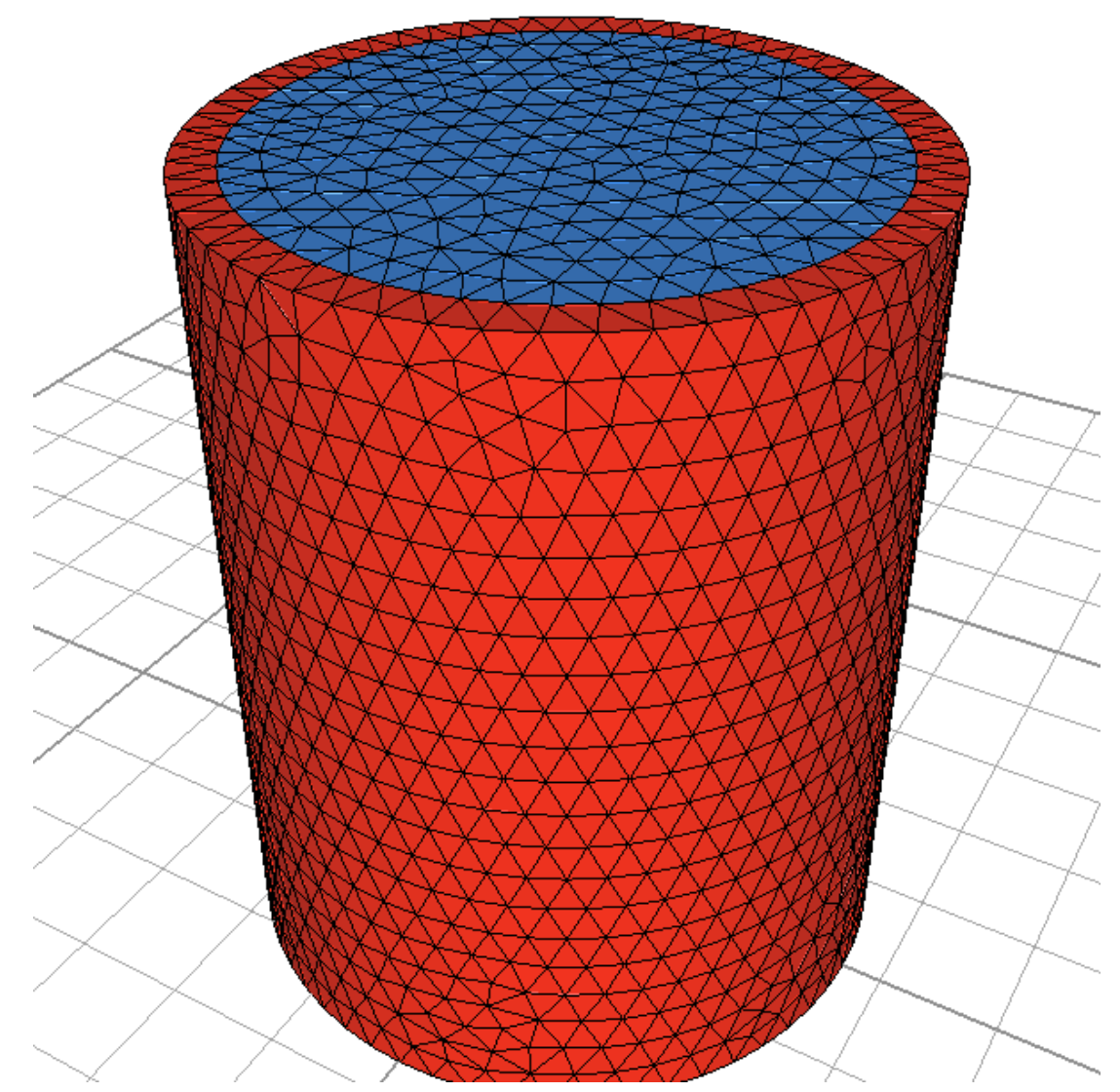

Fig. 1. Initial geometry of the combined fuel and clad. The fuel is touching the clad, so there is no gap between them. 


\section{PHYSICS}

The preliminary test problem that we consider is a mechanical simulation of an oxide fuel pellet. The objective of the test problem is to simulate the evolution of void volume fraction within the fuel pellet under a prescribed mechanical loading. Only intra-granular voids are modeled in this problem $[2,5,6]$. The homogenized material model assumes that these voids are spherical in shape. The physics tested includes the effect of fuel porosity on the elasto-plastic response of the fuel-clad system under compression. Subsequent extensions of the problem would include temperature effects and inter-granular ellipsoidal voids.

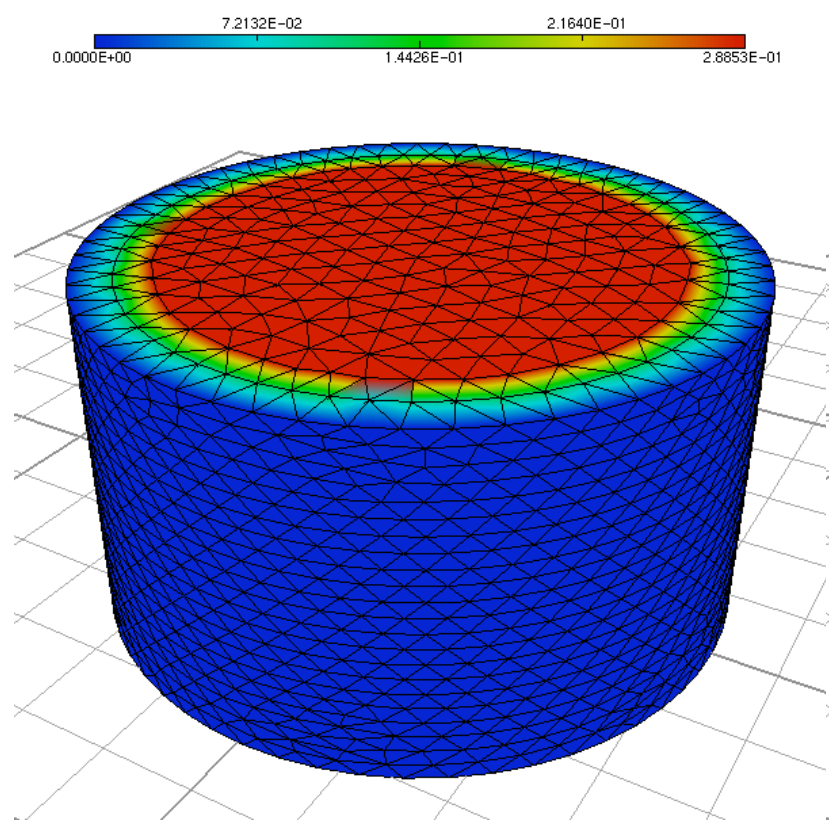

(a)

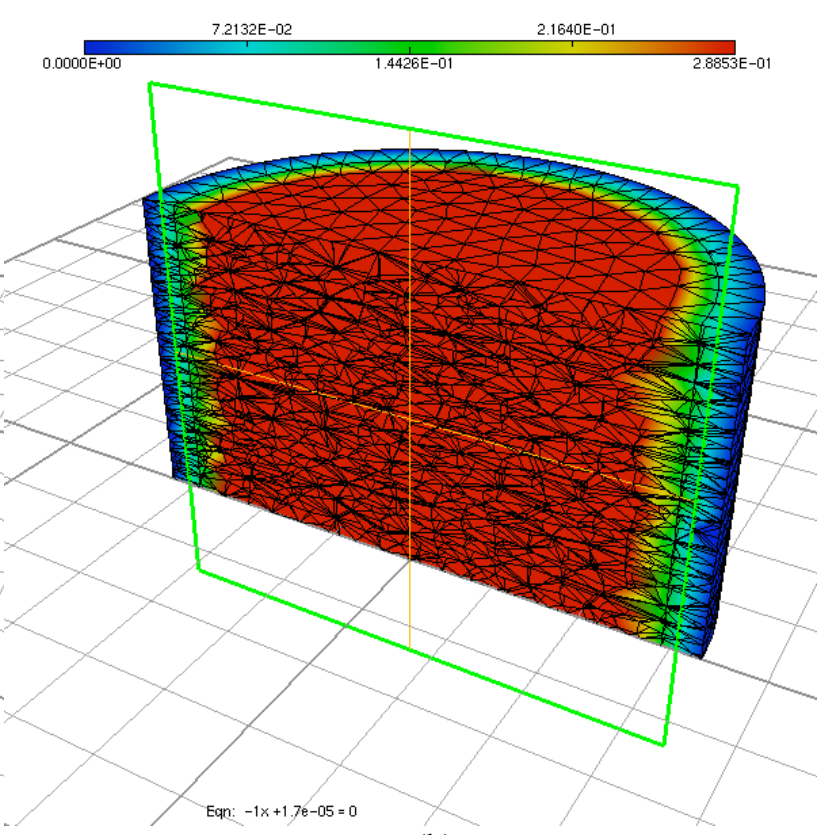

(b)

Fig. 2. Evolution of void fraction within the fuel pellet. (a) A uniform void fraction of 0.3 was imposed over the pellet in the beginning. Due to the applied compressive loading, void fraction decreases over the pellet. The reduction in the void volume fraction within the fuel is uniform throughout the pellet. At the fuel-clad interface, the apparent reduction in void volume fraction to a value of 0.15 is due to the smoothening effect of the software used to generate the contour plots. (b) A cross-sectional view of the void volume fraction within the fuel-clad system.

Two sets of simulations were generated, one with uniform initial void volume fraction (Fig. 2) and the other with random values of the initial porosity (Fig. 3) distributed over the pellet. Both the fuel and clad were assumed to be initially stress free. A prescribed displacement boundary condition (compressive) is applied to the top surface of the pellet and clad. Symmetric boundary conditions are applied at the midplane of the pellet. The fuel pellet is modeled as a poro-elasto-plastic material with a pressure sensitive yield function akin to standard Gurson model [2]. The voids within the fuel can be either in drained or saturated state $[5,6]$. Porosity evolves as a function of the hydrostatic component of plastic strain and is given by $\dot{f}=(1-f) \dot{\varepsilon}_{k k}^{p}$, where, $f=$ void volume fraction, $\dot{f}=$ rate of change of void volume fraction and $\dot{\varepsilon}_{k k}^{p}$ is the rate of change of plastic dilatational strain [3]. A standard isotropic linear elasticity model is used for modeling the mechanical response of clad. Once this preliminary demonstration is completed, this model will be extended to couple the thermal effects with the mechanics and eventually chemistry, microstructure evolution and species redistribution will also be added. 


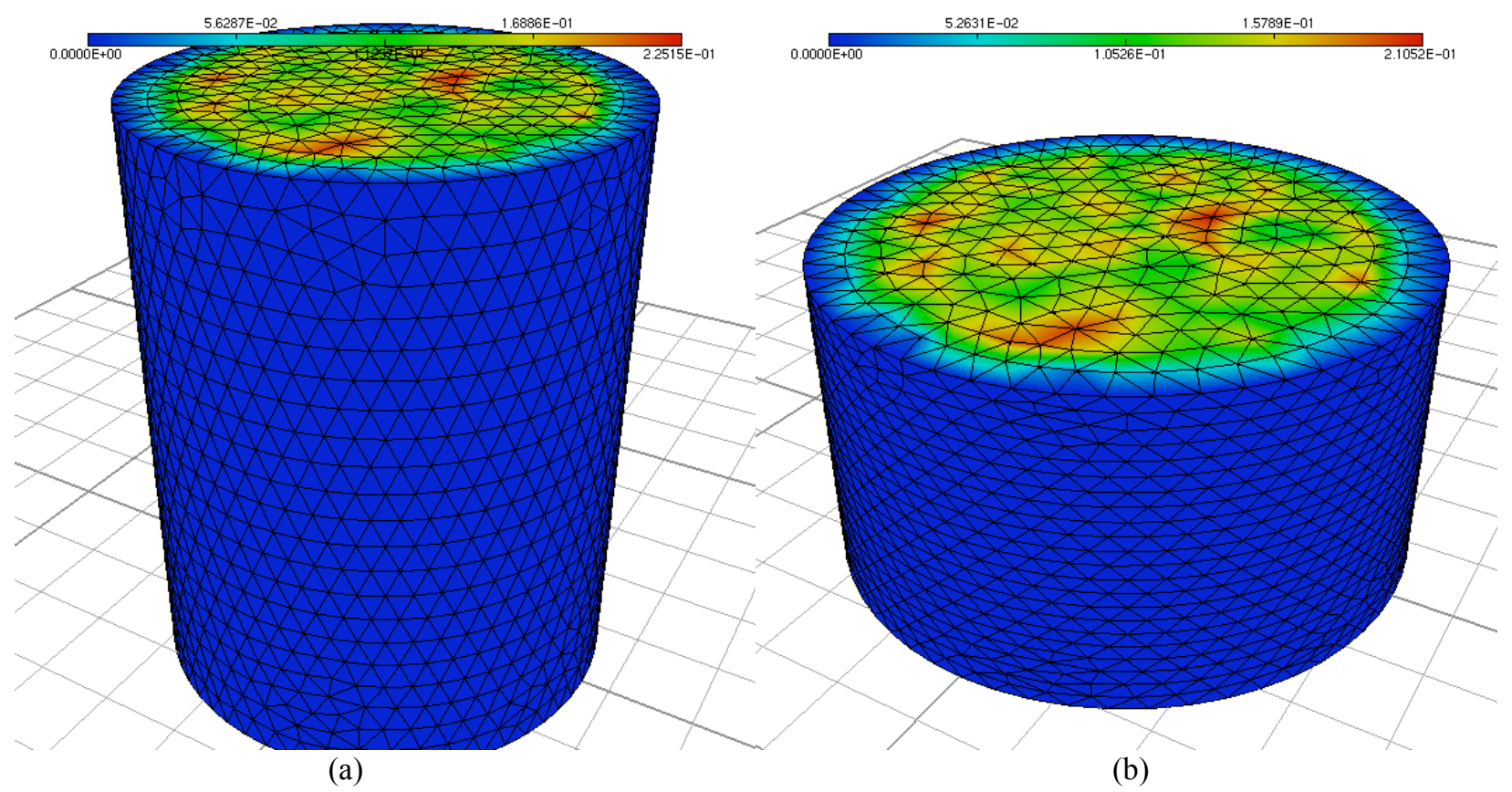

Fig. 3. Evolution of void fraction within fuel pellet. (a) A random void fraction was imposed over the pellet in the beginning. (b) Final void fraction within the fuel-clad system. Void fraction decreases over the pellet due to the applied compressive loading.

\subsection{DATA REQUIREMENTS (INPUT)}

Initial pellet and clad geometries, elasto-plastic properties for oxide fuel and elastic properties of $\mathrm{Zr}$ alloy cladding. The parameters used in these simulations are listed in Appendix A.

\subsection{MESH REQUIREMENTS}

Tetrahedral or hexahedral mesh for fuel pellet and clad. 


\section{EXPECTED RESULTS (OUTPUT)}

1. Spatial stress distribution in the fuel and cladding

2. Spatial void fraction evolution within the fuel

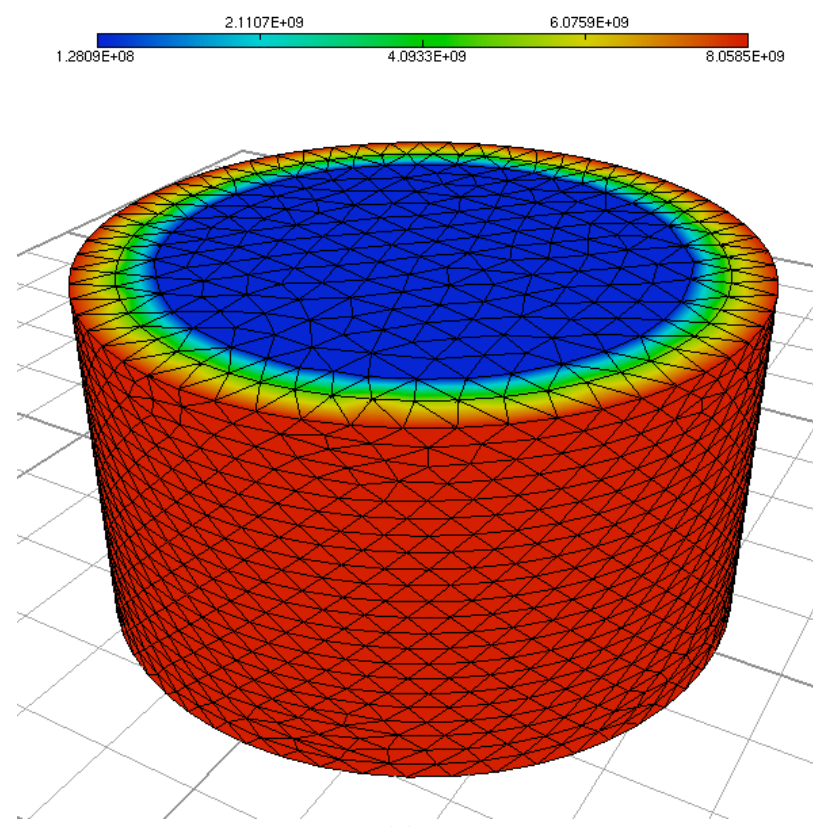

(a)

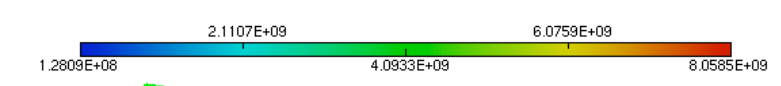

Fig. 4. Evolution of equivalent stress within the fuel pellet and clad. Initial volume fraction of 0.3 inside the fuel pellet was assumed. (a) Under compressive loading the stresses evolve within the fuel and clad. Because of high volume fraction the stress within the fuel is comparatively lower than the stress on the clad. The stress distribution is uniform on both the fuel pellet and cladding. The apparent stress gradient visible on the fuel-clad interface is due to the smoothening effect of the contour plotting software. (b) A cross section view of the same figure showing the uniform axial distribution of stress inside the fuel pellet.

Fig: 2 and fig: 3 contain the spatial void fraction evolution result and fig: 4 describe the stress distribution within the fuel and cladding.

A comparative study is conducted for the evolution of volume fraction under compressive loading within the fuel pellet for two conditions:

(a) The radial expansion of the outer surface of the clad is constrained.

(b) Radial expansion of the outer surface of the clad is allowed.

The initial void volume fraction within the fuel was assumed to be $f=0.3$. The results are given in fig: 5. Under constrained deformation the fuel pellet could not deform freely which resulted in generation of higher hydrostatic stress inside the pellet. This caused the volume fraction to drop from 0.3 to 0.27 . On the other hand, the free deformation of the pellet and cladding generated lesser hydrostatic stress, which resulted in decrease in void volume fraction from 0.3 to 0.29 only. Fig: 6 shows how the void volume fraction varies along any arbitrary diameter on the fuel-clad system. The diameter has been normalized between -0.5 to +0.5 to ensure the generality of the distribution. Due to compression the void volume fraction decreases and the reduction is uniform throughout the fuel system. The clad has zero void volume fractions. The apparent gradient visible in the variation of void volume fraction in fig: 5 are due to the contour plotting mechanism used by the software to generate these figures. 


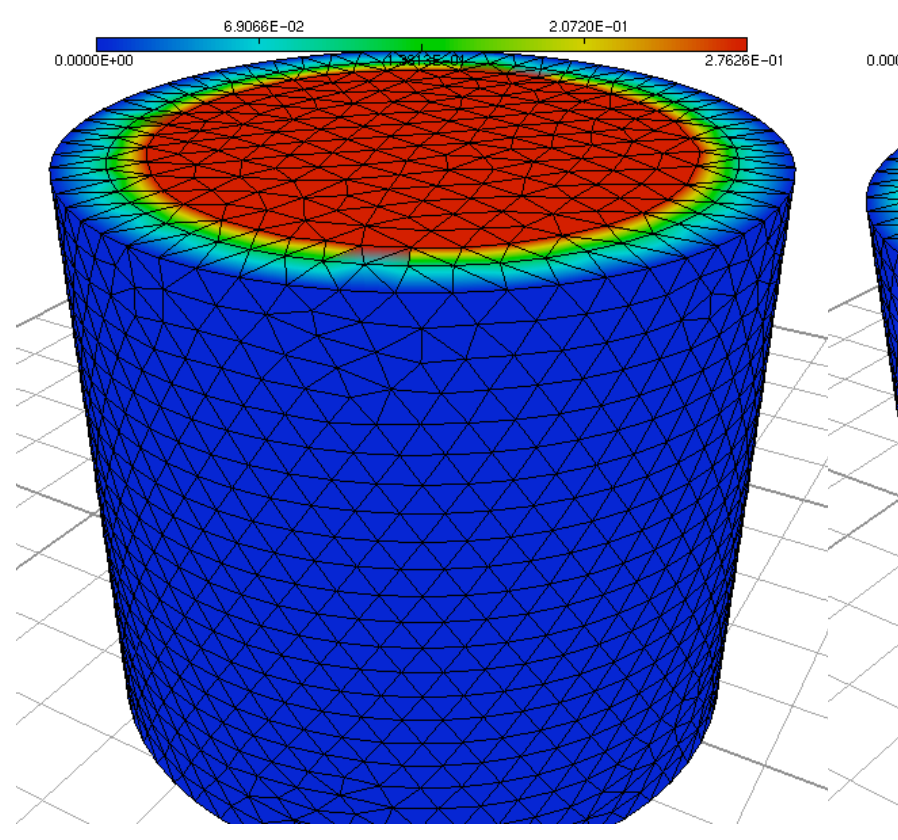

(a)

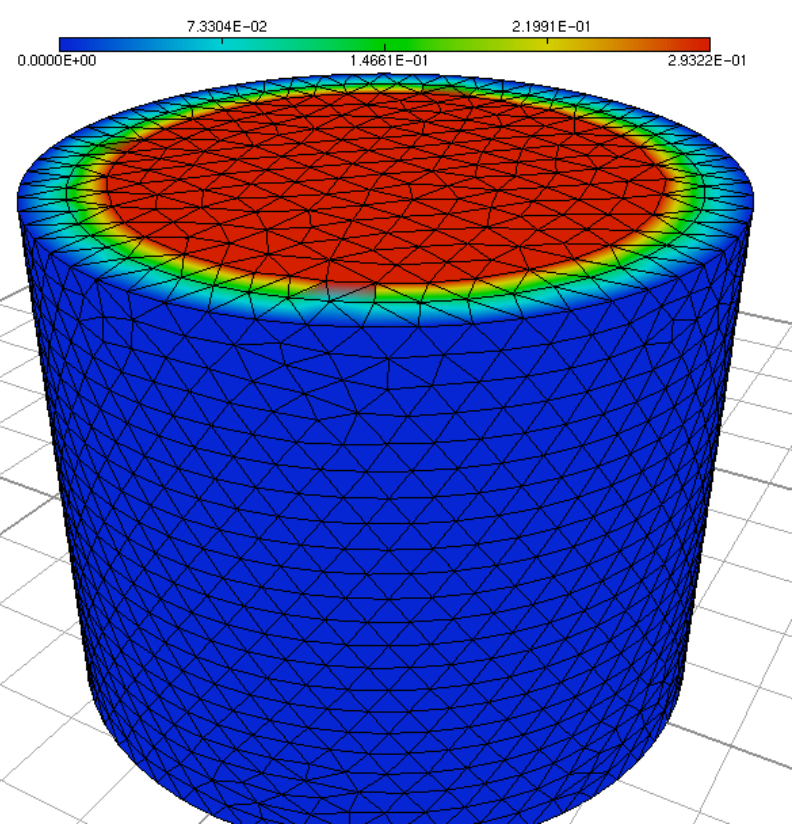

(b)

Fig. 5. A comparative study for the evolution of volume fraction within the fuel pellets under two conditions: (a) The radial expansion of the outer surface of the clad is constrained. (b) Radial expansion of the outer surface of the clad is allowed. The initial void volume fraction within the fuel was assumed to be $f=0.3$. For the constrained case the void volume fraction reduced from 0.3 to 0.27 (approximately $10 \%$ reduction). For the second case only $3 \%$ reduction in void volume is observed. The distribution of void volume fraction along any diameter within this fuel-clad system is given in fig: 6 .

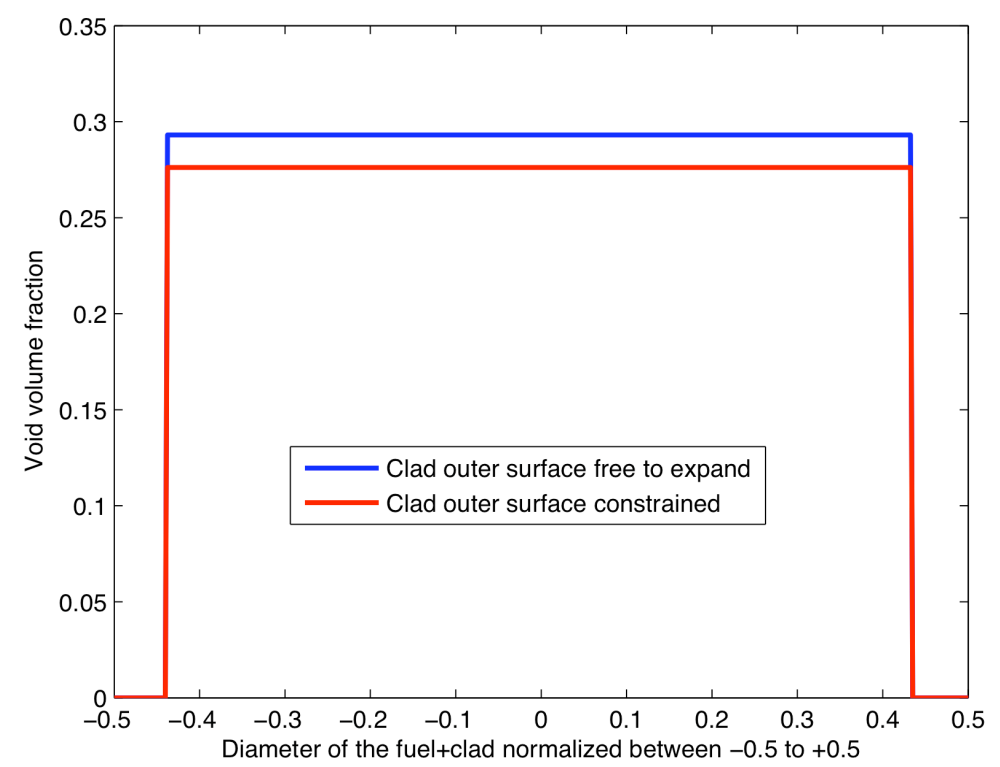

Fig. 6. Variation in the void volume fraction along any diameter (normalized between -0.5 to +0.5 ) inside the fuelclad system. Initially the void volume inside the fuel was $f=0.3$ and zero within the clad. After compression the void volume fraction decreases uniformly inside the fuel. This figure shows the distribution of $f$ within the fuel and the clad after compression. For the case where the outer surface of the clad was restrained from radial expansion, the hydrostatic stress generation within the fuel was more resulting in more reduction of void volume fraction than the case with free radial expansion of the outer surface of the clad. 


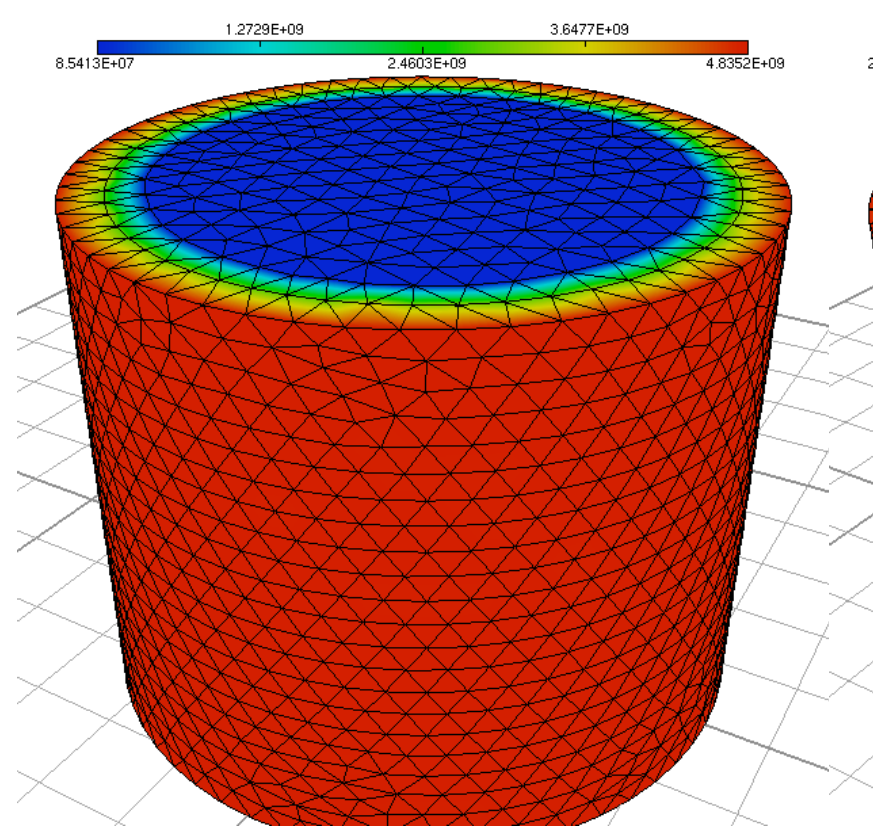

(a)

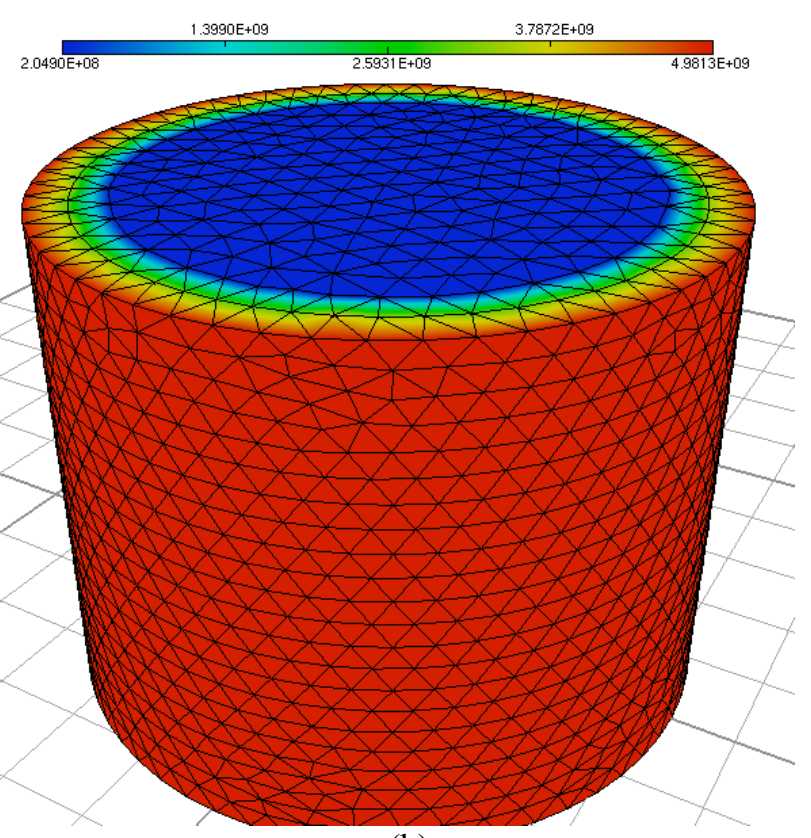

(b)

Fig. 7. A comparative study for the evolution of stress within the fuel-clad assembly is conducted for: (a) Fuel pellet containing initial porosity $f=0.3$, (b) Fuel pellet without porosity. The fuel pellets with pores show a stress distribution of $85 \mathrm{MPa}$; whereas, the other pellet with no porosity reach stress level around $204 \mathrm{MPa}$.

Another comparative study for the evolution of stress within the fuel-clad assembly is conducted for:

(a) Fuel pellet containing initial porosity $f=0.3$.

(b) Fuel pellet without porosity.

Under compressive displacement loading, the fuel pellet with pores showed a uniform equivalent stress distribution of $85 \mathrm{MPa}$ at the end of deformation. Whereas, the other pellet with no porosity [4,7], displayed uniform stress distribution of $204 \mathrm{MPa}$. The simulation results are shown in fig: 7 . This comparison shows the importance of including the effect of void volume fraction in the analysis of oxide fuels.

In addition to the above results, later extensions of the model would result in

1. Thermo-mechanical evolution of porosity and gap closure leading to mechanical contact

2. Chemical phases distribution within the pellet

3. Species distribution in the pellet

4. Fission gas release from fuel

5. Microstructure evolution 


\section{REFERENCES}

1. Olander, D., "Nuclear fuels - Present and future", Journal of Nuclear Materials, 389, 2009, $1-22$.

2. Gurson, A. L., "Continuum Theory of Ductile Rupture by Void Nucleation and Growth: Part 1 - Yield Criteria and Flow Rules for Porous Ductile Media", Journal of Engineering Materials and Technology, 1977, 2 - 15.

3. Aravas, N., "On the numerical integration of a class of pressure-dependent plasticity models", International Journal for Numerical Methods in Engineering, 24, 1987, 1395 - 1416.

4. Nukala, P. K. V. V., "A return mapping algorithm for cyclic viscoplastic constitutive models", Computer Methods in Applied Mechanics and Engineering, 195, 2006, 148 - 178.

5. Vincent, P. G., Monerie, Y. and Suquet, P., "Ductile damage of porous materials with two populations of voids", Comptes Rendus de I Academie des Sciences - Series IIB - Mechanics, 336 (1 -2), 2008, $245-259$.

6. Vincent, P. G., Monerie, Y. and Suquet, P., "Porous materials with two populations of voids under internal pressure: II. Growth and coalescence of voids", International Journal of Solids and Structures, 46, 2009, 507 - 526.

7. Simo, J. C. and Hughes, T. J. R., "Computational Inelasticity”, Springer, 1998.

8. “ADVENTURE_Solid User Manual”, May, 2001.

9. Olander, D. R., "Fundamental Aspects of Nuclear Reactor Fuel Elements", Energy Research and Development Administration, 1976. 
APPENDIX A.

\section{LIST OF MATERIAL PROPERTIES}





\section{APPENDIX A. LIST OF MATERIAL PROPERTIES}

Table: Material Properties

\begin{tabular}{|c|c|c|}
\hline Material Property & Oxide Fuel & Clad \\
\hline Young's moduli $(\mathrm{GPa})$ & 174.92 & 160 \\
\hline Poisson's Ratio & 0.316 & 0.33 \\
\hline Yield Stress $(\mathrm{MPa})$ & 145 & -- \\
\hline $\begin{array}{c}\text { Hardening Parameter } \\
(\mathrm{GPa})\end{array}$ & 2.1 & -- \\
\hline Density $(\mathrm{kg} / \mathrm{m} 3)$ & 10660.0 & 7818.0 \\
\hline
\end{tabular}

